\title{
Necessidades das famílias em enfermaria pediátrica: \\ a percepção dos próprios atores
}

\section{The needs of families in pediatric nursing from their own perspective}

\author{
Regina Helena Vitale Torkomian Joaquim ${ }^{1}$, Letícia Maria Barbano², \\ Tatiana Barbieri Bombarda ${ }^{3}$
}

http://dx.doi.org/10.11606/issn.2238-6149.v28i2p181-189

Joaquim RHVT, Barbano LM, Bombarda TB. Necessidades das famílias em enfermaria pediátrica: a percepção dos próprios atores. Rev Ter Ocup Univ São Paulo. 2017 maio-ago.;28(2):181-9.

RESUMO: O presente trabalho visou identificar a percepção de familiares sobre suas necessidades na vivência do processo de hospitalização infantil. Por meio do uso da técnica de grupo focal, foram realizados 11 encontros com um total de 36 familiares participantes. Os dados obtidos foram analisados pela Análise de Conteúdo Temática e agrupados em quatro categorias: desgaste psicoemocional, modificação de rotina, ambiente hospitalar e recursos de suporte. Diante dos apontamentos, verificou-se que as necessidades proferidas pelos familiares vinculam-se a problemáticas relacionadas ao ambiente físico hospitalar, à postura profissional, a dinâmica do serviço e a própria vivência do adoecimento e hospitalização. Concluiu-se que as demandas apresentadas são multidimensionais, visto perpassarem por questões emocionais, organizacionais e relacionadas a rupturas de seu cotidiano. Deste modo, se faz necessário incluir o familiar cuidador na assistência, fator que exige o desenvolvimento de um trabalho interdisciplinar efetivo, sendo o terapeuta ocupacional um profissional potencial para auxiliar na minimização das dificuldades estratificadas.

DESCRITORES: Família; Hospitalização; Cuidado da criança; Humanização da assistência; Quartos de pacientes/normas.
Joaquim RHVT, Barbano LM, Bombarda TB. The needs of families in pediatric nursing from their own perspective. Rev Ter Ocup Univ São Paulo. 2017 May-Aug.;28(2):181-9.

ABSTRACT: This study aimed at identifying the perception of families on their needs when experiencing the process of child hospitalization. Using the focal group technique, we carried out 11 meetings with a total of 36 family members. We analyzed the data obtained with Thematic Content Analysis and divided it into four categories: psychological exhaustion, changes in routine, hospital environment and support resources. From the given reports, we verified that family members' needs are associated with problems regarding the hospital environment, health professionals, service dynamics, and the disease and hospitalization experience. We concluded that their demands are multidimensional, considering they comprise emotional and organizational matters associated with changes in routine. This way, the patient's family companion needs to be considered in this process, which demands an effective interdisciplinary work, and the occupational therapist can be considered a potential professional to minimize the difficulties mentioned.

KEYWORDS: Family; Hospitalization; Child Care; Humanization of assistance; Patients' riims/standards.

Pesquisa de Iniciação Científica e Trabalho de Conclusão de Curso em Terapia Ocupacional da aluna Letícia Maria Barbano Universidade Federal de São Carlos (UFSCar). Pôster apresentado na XIX Semana de Estudos de Terapia Ocupacional da UFSCar, II Simpósio de Apresentação de TCC e IC do Curso de Terapia Ocupacional da UFSCar.

1. Universidade Federal de São Carlos. E-mail: joaquimrhvt@gmail.com, regin@ufscar.br

2. Universidade Federal de São Carlos. E-mail: leticiabarbano@yahoo.com.br

3. Universidade Federal de São Carlos. E-mail: tatibb_to@yahoo.com.br

Endereço para correspondência: Departamento de Terapia Ocupacional - UFSCar. Rod. Washington Luis, km 235. São Carlos, SP, Brasil. CEP: 13565-905. 


\section{INTRODUÇÃO}

$\mathrm{O}$ processo de adoecimento e hospitalização infantilé um acontecimento potencialmente perturbador que implica em transformações na rotina de todo o núcleo familiar ${ }^{1}$.

A internação da criança ocasiona sofrimento a cada um dos membros da família, afetando o equilíbrio e os papéis ocupados por eles, fator promotor de desestruturação no contexto familiar ${ }^{2}$.

Diante da hospitalização da criança, a família pode vir a apresentar dificuldades associadas à estruturação das ações, ao nível de comunicação estabelecido, às normas existentes e às condições do ambiente físico institucional ${ }^{3}$.

Fatores como falta de acomodações adequadas para descanso e sono no espaço hospitalar, ruídos de outras famílias e da equipe, além do próprio choro das crianças, associados ao sofrimento pelo período de hospitalização, e a alternância entre o domicílio e o hospital, geram ao familiar desgastes físico e emocional ${ }^{4}$.

Sentimentos negativos, tais como medo, ansiedade, culpa, bem como a brusca mudança de rotina ocasionada pela hospitalização, diminuem a qualidade de vida da família comprometendo as ações de suporte ofertadas por estes ao paciente ${ }^{5}$. Além disso, as condições estruturais ofertadas pela instituição para a permanência do acompanhante familiar atingem diretamente as necessidades humanas básicas como o sono, a alimentação e a higienização pessoal ${ }^{6}$.

Em geral, a área física hospitalar é organizada em função apenas da criança, não contemplando as necessidades do acompanhante. Além disso, o processo de trabalho, as normas e rotinas das unidades, são elaboradas em função das necessidades dos serviços e não dos clientes. Horários de visita, de alimentação e outros são adequados pela conveniência dos serviços e não para favorecimento das demandas familiares? Rumor e Boehs ${ }^{8}$ apontam a necessidade de revisão das normativas institucionais, as quais deveriam ser embasadas também nas demandas das famílias, contribuindo dessa forma para o avanço da humanização da assistência.

Outro fator de desgaste evidenciado na literatura são os conflitos existentes entre familiares e equipe no cotidiano da assistência. Conforme descrito por Collet ${ }^{9}$, as relações entre família e profissionais de saúde são complexas e verticalizadas, sendo uma constante o uso de estratégias de ambas as partes para sublimar os conflitos. Neste contexto, é preciso investir em uma relação dialógica entre os profissionais e o familiar da criança, na busca por compreender suas necessidades e expectativas ${ }^{4}$.
Compreende-se que as necessidades das famílias são multidimensionais e que estas não são por vezes identificadas e incorporadas no processo do cuidado ${ }^{6}$. Ayvazian ${ }^{10}$ relata que o cuidado à família ainda não tem sido incorporado de forma ativa na prática assistencial apesar de ser foco de discussão interprofissional. Empoderar a família no processo de cuidado por meio de ações educativas, pode vir a prevenir internações recorrentes e prover melhoras nesta relação ${ }^{4}$.

Armond e Boemer ${ }^{11}$ expressam que a busca por compreensão do modo como os familiares lidam com a hospitalização permitem novas configurações assistenciais, o que envolve a inclusão da família no processo de cuidado. A estruturação de intervenções envolvendo as particularidades e o potencial de cada família ofertará elementos para o desenvolvimento de políticas institucionais pautadas na realidade dos sujeitos a serem cuidados ${ }^{8}$.

A experiência da família pode ser facilitada quando houver apoio da equipe hospitalar, recebimento de informações sobre as causas da doença e prognóstico, valorização do sofrimento e compreensão de suas vulnerabilidades ${ }^{12}$.

De acordo com a lei 8.069 de 1990, a qual dispõe sobre o estatuo da criança e adolescente, é referido no artigo 12 o dever das instituições de saúde ofertar condições para a permanência em tempo integral de um dos pais ou responsável, nos casos de internação de criança ou adolescente ${ }^{13}$. Assim, é importante entender as dificuldades vivenciadas pelos familiares no âmbito hospitalar, considerando a existência de impactos prévios promovidos pela própria situação da enfermidade.

O presente trabalho visou identificar a percepção sobre as necessidades de familiares que vivenciam o processo de hospitalização junto à criança, como modo de estratificar demandas potenciais para atuação da terapia ocupacional centrada na família.

\section{METODOLOGIA}

Trata-se de um estudo transversal, de abordagem qualitativa ${ }^{14}$, em que se utilizou grupo focal para a coleta de dados e análise temática para organização e descrição dos dados.

A pesquisa foi realizada em uma enfermaria pediátrica na Santa Casa de Misericórdia de uma cidade do interior do Estado de São Paulo, que atende usuários do Serviço Único de Saúde - SUS. Estruturalmente, esta enfermaria organiza-se em quartos distribuídos em função dos problemas de saúde: respiratório, gastrointestinal, pré 
Joaquim RHVT, et al. Necessidades das famílias em enfermaria pediátrica. Rev Ter Ocup Univ São Paulo. 2017 maio/ago.;28(2):181-9.

ou pós-cirúrgico, e isolamento para casos infecciosos. O tempo médio de hospitalização oscila entre 7 a 15 dias, sendo a permanência das crianças e famílias variável devido ao quadro clínico.

Participaram desta pesquisa familiares ou membros da rede social de suporte das crianças que se encontravam hospitalizadas no período de outubro de 2013 a fevereiro de 2014. Durante este período o pesquisador responsável esteve no hospital semanalmente. Na chegada à instituição realizava levantamento, junto à equipe de enfermagem, acerca da presença de acompanhantes das crianças internadas que possuíam idade entre 0 e 12 anos, efetivando, a beira leito, convite de participação para o grupo. Foram excluídos familiares que se recusaram a participar e aqueles que já haviam participado por uma vez do grupo, fato que implicou em não ter havido em algumas semanas a realização do grupo.

Não foi considerado frequência ou período temporal do familiar na enfermaria como acompanhante, visto o desejo de se estratificar percepções tanto daqueles recém-chegados a rotina do hospital, como aqueles que ali já estavam por diversos dias.

O grupo ocorria em um dos quartos, tendo os encontros, em média, duração de 30 minutos, sendo este tempo definido pela dinâmica da enfermaria pediátrica.

Metodologicamente optou-se pelo emprego do grupo focal, que segundo Iervolino e Pelicioni ${ }^{15}$ consiste em uma técnica realizada para o entendimento dos diferentes posicionamentos acerca de um fato, prática ou serviço. O grupo focal pode ser considerado uma entrevista de grupo, consistindo a essência do método a interação entre os participantes e o pesquisador que objetiva colher dados a partir do debate focado em tópicos específicos e diretivos ${ }^{15}$. Após aceite do convite e acompanhamento dos familiares até o quarto destinado como local de desenvolvimento do grupo apresentava-se o Termo de Consentimento Livre e Esclarecido e com a assinatura iniciava-se o grupo por meio de um recurso disparador.

Os disparadores utilizados envolveram trechos de telenovela com cenas de uma criança hospitalizada, figuras de crianças internadas acompanhadas por seus pais associadas a uma questão norteadora: Como tem sido a vivência de acompanhar a criança no processo de hospitalização? Tais recursos facilitavam o início das expressões, tendo o pesquisador função de estimular a manutenção das trocas e do enfoque temático, à emersão das percepções e moderação para a estratificação da visão coletiva referente as dificuldades vivenciadas durante a hospitalização.

Os dados foram registrados com um gravador e em diários de campo. As sessões foram transcritas e, juntamente com o Diário de Campo, analisadas com base na técnica de "Análise de Conteúdo Temática"14, em que se verifica a repetição dos temas no conteúdo do material analisado, com base em três etapas:

1) Pré-Análise do material coletado: se refere a leitura flutuante dos textos do diário de campo e das transcrições do áudio coletado, e posterior revisão para verificar se estes dados contemplavam ou não as hipóteses da pesquisa;

2) Exploração do material: organização do material coletado e análise dos relatos em categorias temáticas;

3) Interpretação dos Resultados: a partir da categorização dos relatos realizada a interpretação dos resultados com base em referenciais teóricos.

Como critério de finalização da coleta de dados utilizou-se a saturação ${ }^{16}$.

Este estudo foi aprovado pelo Comitê de Ética em Pesquisa com Seres Humanos conforme parecer $n^{\circ}$ 375.606 e teve consentimento da instituição hospitalar, respeitando-se a Resolução CNS 466/12.

\section{RESULTADOS}

Ao final do estudo foram obtidas 11 sessões de grupo focal com um total de 36 participantes, 30 mulheres e 6 homens, constituindo o grau de parentesco, mães, pais e avós.

Os dados obtidos foram agrupados em quatro categorias, a saber: desgaste psicoemocional, modificação de rotina, ambiente hospitalar e recursos de suporte.

\section{Desgaste Psicoemocional}

Nesta categoria foram contempladas manifestações emocionais emergidas pela vivência da internação, pela condição clínica da criança, pelos procedimentos médicos adotados, entre outros.

Percebeu-se nos relatos dos familiares uma diversidade emocional que perpassavam por preocupação, medo, cansaço, apatia, impotência, aspectos que configuram um quadro gerador de sofrimento.

Os familiares relataram sobre o atual e o futuro estado de saúde do filho, manifestaram expressões relacionadas ao desespero pela situação enferma da criança, seja pela notícia da doença, seja pelos procedimentos médicos adotados durante o tratamento. Também foi sinalizado sobre o medo da criança sofrer pela doença e procedimentos, ou 
até mesmo acerca do medo de perdê-la por evolução do quadro. Além disso, muitas vezes a angústia de não ter um diagnóstico preciso ou o tratamento não estar funcionando como o esperado foi apontado como fator que corrobora para intensos desgastes.

\begin{abstract}
"Tem vários sentimentos dentro da gente... não é só medo, só cansaço... É insegurança, desconforto, angústia de ver seu filho ali, deitado, e você não poder fazer nada”. (C4)

"[Se] eles vão entrar na sala, jáfica preocupado, resultado de exames, que a gente fica esperando... A gente não sabe como ele vai estar daqui a pouco...". (C12)
\end{abstract}

Expressões relacionadas à resignação, desânimo e conformismo pela internação, como se não houvesse mais nenhuma alternativa e a única opção fosse estar ali também apareceram.

“Tem que acostumar, né?”. (C22)

"Eu nem fico mais triste, nem alegre, nem nada mais". (C18)

Alguns dos familiares manifestaram empatia, demonstrando se colocar no lugar da criança, desejando vivenciar as experiências no lugar dela.

Ontem mesmo, eu falava 'Filha, passa essa dor pra mãe! Vai embora para casa que eu fico no seu lugar!’. (C15)

Foi percebida preocupação dos familiares em não demonstrar-se frágil à criança, visto entendimento do papel familiar findar-se em dar força e apoio.

“... Querendo ou não, você tem que se mostrar forte pra criança". (C20)

"A gente só pode transmitir segurança [...] não chorando perto dele, não é?! Tentando fazer ele se sentir seguro”. (C36)

\section{Modificações na rotina}

Nesta categoria agrupou-se informações acerca das faltas no trabalho, ausência dos outros filhos e prejuízos no autocuidado, fator que afeta diretamente a rotina dos familiares.

Em virtude do processo de adoecimento e hospitalização, muitos dos participantes relatam problemas com o trabalho, inclusive sendo referido em um dos casos perda do vínculo empregatício devido ao tempo demasiado de permanência no âmbito hospitalar.

"Ela [empregadora] me chamou e falou: eu sei que é duro, que é dificil, mas se você não vier dar aula, você vai perder seu emprego". (C18)

“... a empresa não quer saber se você é pai ou mãe, o que tá passando... no começo, um, dois dias, a gente tem flexibilidade no emprego, passou disso aí fica mais complicado...". (C35)

Relatos sobre cansaço apareceram vinculados a percepção de sobrecarga ocasionada tanto pela situação da internação, quanto pela falta de rede de suporte. A necessidade de reorganização temporária da rotina familiar explicitamente pode ser notada nos relatos referentes a busca por suporte de outras figuras sociais para respaldo dos familiares durante a estadia, seja para revezamento como acompanhante, seja para oferta de ajuda para cuidar de instâncias que os familiares não podem se ater devido a permanência no hospital. Sendo estas, desde problemas pessoais diversos à situação; possibilidade de perda de emprego; necessidade de cuidado de outros filhos e do lar; até auxílio para as necessidades internas, como reabastecimento de roupas e utensílios pessoais utilizados durante a internação.

"Cansa a criança, cansa a gente. Tem muita criança lá em casa, meu marido não pode ficar vindo que ele trabalha, e não tem como ficar trocando um ou outro". (C26)

"Pra mim eu fico com a cabeça aqui, pensando no outro [filho] lá... com ele [filho hospitalizado] aqui... se eu fico lá, fico com a cabeça pensando nele aqui...". (C17)

As dificuldades citadas implicam, por vezes, no movimento de abnegação, ou seja, consiste em prejuízos no desempenho dos cuidados pessoais e atividades laborais. A permanência integral no hospital pela indisponibilidade de outros membros da família revezar acompanhamento da criança implica até mesmo nas ações de higiene pessoal (tomar banho, escovar os dentes, trocar de roupa, entre outros) do acompanhante, fator que o torna suscetível ao maior desgaste. Em alguns momentos, percebeu-se a abnegação associada ao dever materno/paterno de zelar pela criança, priorizando suas necessidades.

Problemas de adaptação à rotina da internação são associados às práticas de cuidado com a criança, sendo 
relatado pelos familiares dificuldades de adaptação aos horários de alimentação e medicamentos; a um ambiente diferente e sem possibilidade de preenchimento do tempo ocioso; assim como dificuldade de descansar pela noite.

"Ele tá acostumado a comer quase toda a hora, e aqui não, tem hora certa. Ele quer leite, está vendo, trouxeram chá, eu tive que ir lá buscar leite”. (C4)

"À noite, você tem que ficar ali mesmo. Medicação, são as enfermeiras que dão, você tem que ficar ali, mãe não dorme, fica observando". (C26)

\section{Ambiente hospitalar}

Esta categoria temática envolveu relatos sobre dificuldades atreladas a qualidade do serviço ofertada, rotina ociosa e percepções de inadequações ambientais.

As sensações vivenciadas durante a internação fazem surgir a necessidade de expressar sentimentos e de preencher o tempo ocioso com atividades que distraiam e minimizem os impactos da hospitalização. A falta das atividades ocupacionais e de lazer faziam os acompanhantes se queixarem do tédio e da demora no transcorrer do tempo, o que contribuía para estados de ansiedade, inquietação ou apatia.

“É horrivel ficar aqui... as horas não passam...”. (C1)

“... aqui não tem uma tv para a gente se distrair... A gente traz um computador não tem como trabalhar, porque não tem internet... Não que é luxo, é necessidade.... Ai tem ali a salinha [lúdica], a criança vai e não tem nada de atrativo...". (C31)

Críticas relativas à demora no atendimento, em relação a profissionais que não explicam os procedimentos realizados, que não atendem o paciente com atenção e esmero, que não fornecem diagnósticos ou explicações sobre a enfermidade do sujeito, ou ainda relatos sobre situações constrangedoras vivenciadas pelas crianças e seus familiares se constitui como relatos vinculados a qualidade do serviço que afetam diretamente o equilíbrio emocional dos familiares.

"Entrar aqui é em último caso, mas a gente quer uma solução, a gente quer uma resposta do médico... A gente não pode reclamar dos médicos em geral, mas quando há uma falha que o neurologista não atendeu a menina, não dá uma posição, eu achei um absurdo... Eu como profissional não agiria dessa forma”. (C29)

"Ela já estava com a internação na mão e ficou lá embaixo [recepção], mais de duas horas, aguardando, vendo ali na entrada do SAMU, coisas horríveis... Ela ficou observando tudo aquilo [...] tinha um rapaz que tinha tentado suicídio, gritava muito [...] até o policial que estava lá falou 'Nossa, o que essa menina está fazendo aqui ainda?',". (C6)

Muitas vezes a crítica de insatisfação dirigida ao serviço se refletia sobre a estrutura oferecida aos acompanhantes: apenas uma cadeira semi-reclinável para se passar o dia e a noite. Alguns quartos possuíam televisão e havia uma sala lúdica comunitária para as crianças, esta, porém, com apenas alguns livros e uma TV. A falta de asseio e limpeza do local e instrumentos - cama, lençóis, cadeiras e o reduzido conforto foram itens levantados pelos familiares.

"Muita coisa que a gente podia ter.. é um lugar melhor para a gente dormir, porque essas cadeiras estão todas quebradas, a maioria... a gente, que nem, o pai para dormir, dormiu encolhido, a mãe ali, pelo amor de Deus, a vó aqui... Coitada! Não sei como elas conseguiram dormir...". (C11)

Todavia, alguns participantes mostraram-se satisfeitos com o atendimento e atenção dos profissionais, especialmente os do setor de enfermagem. Nos relatos emerge a preferência pelo tratamento hospitalar, o que, segundo os familiares, possibilita maior segurança e cuidado ao paciente.

"Então para mim ela estando internada é bem mais fácil, porque eu internei ela, ficou umas três horas em observação, voltou para casa e piorou de novo... Então ela voltou de novo...Para mim foi bem melhor atendimento, medicação na veia, bem diferente do que você cuidar dentro de casa...Tem horário certo para medicamento, não é?! E eu trabalho, na verdade era para 'mim' estar trabalhando, para 'mim' dificulta um pouco, mas é bem melhor ela aqui”. (C34)

"O atendimento delas está muito bom, a atenção das enfermeiras... Eu acho isso essencial para criança... Não são aquelas que entram carrancudas. Esse sorriso que vocês entram, isso é tão gratificante, até para criança. Brincar na hora de aplicar,...". (C19) 
O suporte oferecido pelo serviço de saúde se mostrou como relevante apoio para os familiares. A opinião médica e de outros profissionais envolvidos no tratamento, o modo de transmitir informações, a atenção e o cuidado na relação foram citados como importantes para a tranquilidade e confiança no serviço hospitalar, bem como relevantes para os familiares sentirem-se em um ambiente mais humanizado.

"No dia que ela ficou internada, a enfermeira chefe lá da UTI, viu que eu estava tão apavorada que a primeira coisa que ela fez foi chegar em mim e falar 'olha mãe, na UTI não pode ficar, mas eu sou mãe e sei que você não vai sossegar enquanto não souber notícia'... Ela passou o telefone da neonatal e o nome de uma moça que ia estar de plantão e eu podia ligar para ver como estava o estado dela [...] então quer dizer, eles cuidam muito bem". (C4)

Apesar de alguns cuidadores relatarem confiança e satisfação, outros se mostraram desconfiados com os cuidados oferecidos. Tal expressão se dava, principalmente, em relação à falta de atenção durante $\mathrm{o}$ atendimento.

"Chegando lá o médico disse que não tinha nada e nem olhou ele direito...". (C10)

"Eu tenho muito medo na hora de aplicar injeção, soro, essas coisas, porque você vê no jornal, acontece cada coisa! Vamos supor, você está com sua filha aqui, dá um remédio errado, mata... Eu já pergunto para que serve, por que tá colocando, por que vai aplicar... A vida do ser humano é muito frágil...". (C16)

\section{Recursos de suporte}

Consistiu no agrupamento das informações sobre recursos de apoio ao enfrentamento da internação.

O recurso manifestado pelos participantes de modo predominante foi a religião, cujo apoio espiritual fazia as pessoas aceitarem os acontecimentos e buscarem sentido, força e esperança para continuarem com seus papéis durante a internação.

"Eu creio que nestes momentos só Deus... Ela veio aqui quase morta... E ela veio pra drenar e ficou na UTI, mas graças a Deus não precisou..., deu derrame no pulmãozinho dela [...] Eu creio que neste momento a família ajuda muito, as companheiras do quarto também dão muita força, mas Deus em primeiro lugar, eu acho que não existe outra coisa a não ser a fé em Deus". (C5)
Em complemento emergiu o apoio da família e do cônjuge, considerando expressões sobre visitas, revezamento na companhia do quarto, ligações telefônicas e suporte externo, como o cuidado da casa e outros filhos. $\mathrm{O}$ fato de outros filhos estarem sob cuidados de parentes deixava os familiares mais tranquilos e disponíveis para se dedicarem ao filho hospitalizado. Algumas famílias apontaram o tempo da visita (trinta minutos) como insuficiente para o número de pessoas que vinham visitar ou o tempo que o filho hospitalizado gostaria que os visitantes ficassem. Houve apontamentos acerca de estreitamento dos laços familiares após o adoecimento e hospitalização da criança.

"O mais importante em um hospital para o acompanhante é o apoio da família [...] a gente quer que alguém chegue e fale 'pode contar comigo... porque hospital é um lugar muito dificil de estar ...". (C29)

“... Eu nunca imaginaria, mas estão [família] ajudando bastante eles estão se 'desdobrando'. Aquela minha prima que veio, fazia anos que eu não via! Eu fiquei até boba de ver ela aqui...". (C27)

Em casos menos mencionados, amigos, cuidadores dos filhos e os próprios colegas de quarto se tornaram um recurso de suporte dos familiares.

"Pessoas que eu imaginei que não daria a mínima e estão ajudando... as horas que você mais precisa [as pessoas ajudam]... fiquei surpresa!'. (C30)

"Ela [colega de quarto] que teve que olhar meu menino para 'mim' tomar banho hoje...". (C23)

\section{DISCUSSÃO}

As famílias apresentaram dificuldades vinculadas a questões emocionais, relacionais e de alterações na rotina. Para tanto, percebe-se que as necessidades proferidas pelos familiares vinculam-se a problemáticas relacionadas ao ambiente físico hospitalar, à postura profissional, a dinâmica do serviço e a própria vivência do adoecimento e hospitalização, visto ser este um momento de incertezas e de rupturas do cotidiano.

Esta configuração denota desgaste físico e emocional. Ramirez ${ }^{17}$ expressa que a doença e a hospitalização requerem adaptação e elaboração da situação vivenciada para maior bem-estar psicossocial e qualidade de vida, considerando que as mudanças 
Joaquim RHVT, et al. Necessidades das famílias em enfermaria pediátrica. Rev Ter Ocup Univ São Paulo. 2017 maio/ago.;28(2):181-9.

familiares e sociais emergidas pelo processo de enfermidade se constituem como fatores de risco para o desenvolvimento de transtornos psicoemocionais.

Nesse sentido, Balling e McCubbin ${ }^{18}$ colocam que manter os pais informados sobre o prognóstico do filho, bem como os procedimentos que serão adotados, exames a serem feitos e tratamento que será levado a cabo, permitem que os pais sintam que têm controle sobre a situação, o que diminui o estresse, ansiedade e sentimentos negativos.

Gomes et al. ${ }^{19}$ afirmam que além do subsídio de familiares (para o rodízio no acompanhamento da internação e suporte em atividades fora do ambiente hospitalar), o momento de receber visitas é importante como um tempo em que é possível desabafar sobre medos e angústias e adquirir coragem para enfrentar a situação. Tal tempo, ao que infere esses dados, é essencial para reestabelecer o contato com a vida fora do hospital e as ocupações que os familiares têm externas àquele ambiente.

A situação de esgotamento físico e psicológico relatada pelos pais é apontada nos estudos de Santos et al. ${ }^{5}$, e Beuter et al. ${ }^{20} \mathrm{e}$ de modo geral, ocorre devido à junção de fatores negativos vivenciados pela internação do filho. É deste cenário que surge a necessidade de expressar sentimentos e compartilha-los com outras pessoas como modo de aliviar tensões, enfrentar a situação, preencher o tempo ocioso e estabelecer laços e vínculos com outros cuidadores a fim de criar um ambiente mais familiar e humanizado.

Acredita-se neste contexto, que as diretrizes da Política Nacional de Humanização como o acolhimento, a ambiência e a clínica ampliada, podem ser estratégias potentes para minimização das necessidades dos familiares encontradas neste estudo, as quais dialogam com os achados da literatura.

Em específico a ambiência que se refere ao espaço físico, social, profissional e de relações interpessoais envolvidas com o cuidado oferecido pelos serviços de saúde, devendo proporcionar atenção acolhedora, resolutiva e humana, considerando a construção de espaços que visem à confortabilidade, à produção de subjetividades, entendida como o encontro entre os sujeitos, e que possam ser utilizados como ferramenta facilitadora do processo de trabalho, ambiente este, aspirado por usuários e profissionais ${ }^{21}$.

$\mathrm{O}$ acolhimento consiste no reconhecimento do que o outro traz como necessidade singular, fator preconizado para sustento da relação entre equipe/serviços e usuário/ população ${ }^{21}$.

Não obstante, visualiza-se o uso de recursos de suporte pelos familiares como a religião, o apoio de figuras sócio-familiares, de outros cuidadores companheiros de quarto e equipe médico-hospitalar, como estratégias que auxiliam no enfrentamento e na redução das dificuldades aqui sinalizadas.

Othero ${ }^{22}$, bem como Gomes et al. ${ }^{19}$ e Beuter et al. ${ }^{20}$, manifestam que a religiosidade se constitui como relevante ferramenta de suporte para a situação de hospitalização, visto que a fé e as orações se configuram como vias importantes para suportar e amenizar o sofrimento, bem como para fortalecimento do engajamento na superação do momento. $\mathrm{O}$ acesso à capela do hospital e o encorajamento por parte dos profissionais de saúde às práticas de oração se mostram, nesta linha, como coadjuvantes no processo de recuperação e resiliência dos familiares.

Outro ponto importante a ser destacado refere-se às modificações na rotina dos familiares, considerando queixas vinculadas a ociosidade, a adaptação ao ambiente e dificuldades vinculadas ao autocuidado, bem como os relatos de modificações no desempenho dos papeis ocupacionais (afastamento do trabalho, distanciamento dos outros filhos, não cumprimento de compromissos externos), aspectos potenciais para a intervenção do terapeuta ocupacional.

\section{Processo de hospitalização infantil: perspectivas de atuação da terapia ocupacional centrada na família}

A partir da configuração das necessidades dos familiares, obtém-se o delineamento de problemáticas que demarcam a família como objeto de intervenção para a terapia ocupacional no campo hospitalar.

Takatori et al. ${ }^{23}$ reconhecem que a família desempenha um importante papel no estabelecimento da saúde da criança hospitalizada, sinalizando o terapeuta ocupacional como um profissional com grandes potencialidades em desenvolver ações de apoio aos familiares. O terapeuta ocupacional possui habilidades técnicas em sua formação para promover em conjunto com os familiares, a construção de estratégias para melhor enfrentamento, o que envolve mediação de conflitos, empoderamento de seus direitos e atendimentos individuais voltados a singularidades de cada acompanhante (resgate de atividades religiosas, de lazer, de autocuidado).

O uso de atividades artesanais, artísticas e de técnicas de relaxamento podem se constituir em recursos importantes de auxílio ao enfrentamento da vivência hospitalar e de mecanismos, mesmo que transitórios, de maior bem-estar. Alvarez ${ }^{24}$ apresenta a intervenção por meio da arte como um modo altamente eficaz para reestabelecer o potencial criativo do sujeito, desenvolver habilidades 
de enfrentamento, auto aceitação e autoconfiança, de forma que estas experiências substituam as vivências negativas do processo de hospitalização, favorecendo o desenvolvimento de resiliência, que é a capacidade do indivíduo se fortalecer e manter-se bem apesar ou com as adversidades que the passam.

O desenvolvimento de propostas de grupo de atividades ${ }^{25}$ voltadas à expressão de sentimentos e emoções advindas da situação de internação contemplariam também, a demanda de apoio aos familiares, visto oferta do espaço de escuta, trocas de vivências e de aproximação com membros da equipe.

O impacto que a hospitalização tem sobre o trabalho do familiar desperta a atenção. $\mathrm{O}$ relato de pais que estavam, segundo eles, sob "ameaça" de perder o emprego ou de pais que perderam o emprego sugere, em nível nacional, uma modificação nas políticas trabalhistas, e, a nível local, uma maior atenção dos profissionais da saúde para abordarem esta questão com os familiares responsáveis. Entre as possíveis ações é destacável, a articulação com as famílias de acordos para que durante a intervenção terapêutica ocupacional com a criança, o familiar dentro de um período pré-estabelecido, sempre que possível, utilize deste tempo para práticas de autocuidado (tomar banho, trocar de roupas, escovar os dentes), sendo informado ao seu retorno acerca do que foi desenvolvido com a criança para que sinta ciente, seguro e participativo.

Por fim, os relatos vinculados à prestação de cuidado ofertado pela equipe e atreladas aos espaços físicos, se faz necessárias ações vinculadas a ambiência. Neste sentido, o terapeuta ocupacional, pautado na Política Nacional de Humanização, pode vir a desempenhar ações de sensibilização e orientação à equipe em relação ao cuidado ofertado e impacto vivenciado pelas famílias; contribuir com indicadores para visualização da gestão de benefícios de horários de visitas ampliadas, auxiliar no planejamento e em modificações ambientais esteticamente mais aconchegantes e ergonomicamente mais funcionais.

\section{CONCLUSÃO}

A realização do grupo focal em uma enfermaria pediátrica do interior de São Paulo permitiu o levantamento de demandas dos familiares que se encontram no âmbito hospitalar em virtude da hospitalização de seus filhos. Foi possível verificar que as famílias apresentaram dificuldades vinculadas a questões emocionais, organizacionais e relacionadas a rupturas de seu cotidiano, aspectos que evidenciam a necessidade destes serem inclusos nas práticas assistenciais da instituição.

A atuação centrada na família se faz presente no discurso da equipe hospitalar, contudo a assistência familiar ainda não está de forma ativa incorporada na prática de cuidado em muitos hospitais. A partir das dificuldades dos familiares estratificadas neste estudo, verificou-se uma problemática de ordem multidimensional, fator que implica na necessidade da elaboração de um plano de cuidado interdisciplinar efetivo.

\section{REFERÊNCIAS}

1. Quirino DD, Collet N, Neves AFGB. Hospitalização infantil: concepções da enfermagem acerca da mãe acompanhante. Rev Gaúcha Enferm (Porto Alegre). 2010;31(2):300-6. doi: http://dx.doi.org/10.1590/S1983-14472010000200014.

2. Hayakawa LY, Marcon SS, Higarashi IH. Alterações familiares decorrentes da internação de um filho em uma unidade de terapia intensiva pediátrica. Rev Gaúcha Enferm. (Porto Alegre). 2009;30(2):175-82.

3. Xavier DM, Gomes GC, Salvador MS. O familiar cuidador durante a hospitalização da criança: convivendo com normas e rotinas. Esc Anna Nery. 2014;18(1):68-74. http://dx.doi. org/10.5935/1414-8145.20140010.

4. Gomes GC, Erdmann AL, Oliveira PK de, Xavier DM, Santos SSC, Farias DHR. A família durante a internação hospitalar da criança: contribuições para a enfermagem.

Esc Anna Nery. 2014;18(2):234-40. http://dx.doi. org/10.5935/1414-8145.20140034.

5. Santos LF, Oliveira LMAC, Barbosa MA, Siqueira KM, Peixoto MKAV. Reflexos da hospitalização da criança na vida do familiar acompanhante. Rev Bras Enferm. 2013;66(4):473-8. http://dx.doi.org/10.1590/S003471672013000400002 .

6. Morais RCM, Souza TV, Oliveira ICS. A (in)satisfação dos acompanhantes acerca da sua condição de permanência na enfermaria pediátrica. Esc Anna Nery. 2015;19(3):401-8. http://dx.doi.org/10.5935/1414-8145.20150053

7. Gomes GC. Compartilhando o cuidado à criança: refletindo o ser família e construindo um novo modo de cuidar a partir da vivência na internação hospitalar [tese]. Santa Catarina: Universidade Federal de Santa Catarina; 2005. 
8. Rumor P, Boehs A. O impacto da hospitalização infantil nas rotinas das famílias monoparentais. Rev Eletrônica Enfermagem. 2013;15(4):1007-15. doi: http://dx.doi. org/10.5216/ree.v15i4.19464

9. Collet N. Criança hospitalizada: participação das mães no cuidado [tese]. Ribeirão Preto: Universidade de São Paulo; 2001.

10. Ayavazian A. El centro de alumbramento y lacuracion familiar. In: Hall JE, Weaver BR. Enfermería em salud comunitaria: un enfoque de sistemas. $2 \mathrm{a}$ ed. Washington: OMS; 1990. cap.26, p.466-71.

11. Armond LC, Boemer MR. Convivendo com a hospitalização do filho adolescente. Rev Latino-am Enfermagem. 2004;12(6):924-32. doi: http://dx.doi.org/10.1590/S010411692004000600012.

12. Pinto JP, Ribeiro RC, Silva CV. Procurando manter o equilíbrio para atender suas demandas e cuidar da criança hospitalizada: a experiência da família. Rev Latinoam Enfermagem. 2005;13(6):974-81. doi: http://dx.doi. org/10.1590/S0104-11692005000600009.

13. Brasil. Ministério da Saúde. Estatuto da Criança e do Adolescente. Brasília, DF; 1991. Disponível em: http:// www.planalto.gov.br/ccivil_03/leis/L8069Compilado.htm.

14. Minayo MCS. O desafio do conhecimento: pesquisa qualitativa em saúde. São Paulo: Hucitec; 2007.

15. lervolino SA, Pelicioni MCF. A utilização do grupo focal como metodologia qualitativa na promoção da saúde. Rev Esc Enferm USP. 2001;35(2):115-21. http://dx.doi. org/10.1590/S008062342001000200004.

16. Fontanella BJB, Ricas J, Turato ER. Amostragem por saturação em pesquisas qualitativas em saúde: contribuições teóricas. Cad Saúde Pública. 2008;24(1):17-27. doi: http:// dx.doi.org/10.1590/S0102-311X2008000100003.

17. Ramirez MCG. El Nino y adolescente com uma enfermedad crônica o discapacitante. In: Assumpção Junior FB, Kuczynski E. Situações psicossociais na infância e na adolescência. São Paulo: Atheneu; 2008. p.188-9, 191-3, 195 e 197.

18. Balling K, McCubbin M. Hospitalized children with chronic illness: parental caregiving needs and valuing parental expertise. J Pediatr Nursing. 2001;16(2):110-19. doi: http:// dx.doi.org/10.1053/jpdn.2001.23157.

19. Gomes GC, Erdmann AL, Busanello J. Refletindo sobre a inserção da família no cuidado à criança hospitalizada. Rev Enferm UERJ. 2010;18(1):143-7.

20. Beuter M, Brondani CM, Szareski C, Cordeiro FR, Roso CC. Sentimentos de familiares acompanhantes de adultos face ao processo de hospitalização. Esc Anna Nery. 2012;16(1):134-40. doi: http://dx.doi.org/10.1590/S141481452012000100018 .

21. Brasil. Ministério da Saúde, Secretaria de Atenção à Saúde, Núcleo Técnico da Política Nacional de Humanização. Ambiência. Brasília; 2006. Disponível em: http://www. saude.sc.gov.br/hijg/gth/Ambi\%C3\%AAncia.pdf.

22. Othero MB. Terapia ocupacional na atenção extrahospitalar oferecida pelo hospital. Cad Ter Ocup UFSCar. 2012;20(2):195-202. doi: http://dx.doi.org/10.4322/ cto.2012.019.

23. Takatori M, Oshiro M, Otashima C. O hospital e a assistência em terapia ocupacional com a população infantil. In: De Carlo MMRP, Luzo MCM. Terapia ocupacional: reabilitação física e contextos hospitalares. São Paulo: Roca; 2004. p.256-75.

24. Alvarez CS. Arte terapia em la hospitalización infantil: interaciones entre los acompañantes y los niños hospitalizados [Dissertação]. Valladollid, ES: Faculdad de Educación y Trabajo Social, Universidad de Valladollid; 2013.

25. Ballarin MLGS. Algumas reflexões sobre grupos de atividades em Terapia Ocupacional. In: Padua EMM, Magalhães LV. Terapia ocupacional teoria e prática. 4a ed. Campinas, SP: Papirus; 2008. p.63-78. 